\title{
ANALISIS FAKTOR-FAKTOR PERILAKU PEMBELIAN ONLINE (E-COMMERCE) KONSUMEN MAHASISWA FAKULTAS EKONOMI DAN BISNIS UNIVERSITAS PALANGKA RAYA
}

\author{
Deddy Rakhmad Hidayat ${ }^{1 *}$ dan Peridawaty ${ }^{2}$ \\ 1,2 Fakultas Ekonomi dan Bisnis Universitas Palangka Raya \\ *Corresponding : deddyrakhmadhidayat@feb.upr.ac.id
}

CHRONICLE
Article History:
Received November 7, 2020
Accepted May 18, 2021

\section{Keywords:}

Online buying consumer behavior, perceived benefits, perceived risks, psychological factors, hedonic motivations and Website design

\begin{abstract}
This study was made to examine the determinants of online buying behavior (e-commerce). Factors such as perceived benefits and risks, psychological factors, hedonic motivation and website design are factors that influence the online buying cunsumer behavior. The research method was carried out using a quantitative approach, with collecting data using a questionnaire as a data collection instrument. The respondents used were 100 FEB UPR students in Palangka Raya. The data analysis technique in this study used multiple linear regression with SPSS software. The Result perceived benefits have a significant effect on Online buying Consumer Behavior is accepted. The perceived risks that is accepted has a significant effect on Online Buying Consumer Behavior is accepted. Hedonic motivations has a significant effect on Online Buying Consumer Behavior is accepted. Psychological factors have a significant effect on Online Buying Consumer Behavior is accepted. Website Design has a significant effect on Online Buying Consumer Behavior is accepted. The variables of perceived benefits, perceived risks, hedonic motivations, psychological factors, and Website design simultaneously have a significant effect on online consumer buying behavior.
\end{abstract}

\section{Latar Belakang}

Kedatangan internet telah benar-benar mengubah cara bisnis yang dilakukan di seluruh dunia. Konsumen saat ini memiliki banyak saluran melalui mana mereka dapat berinteraksi dengan bisnis. Salah satu alternatif yang tersedia bagi mereka adalah e-commerce. Istilah e-commerce dapat didefinisikan sebagai lingkungan elektronik tempat pembeli dan penjual bertemu untuk bertukar produk, layanan dan bahkan informasi. Close dan Kukar-Kinney (2010) menunjukkan bahwa perilaku belanja online menunjukkan aktivitas membeli barang atau jasa di internet. Telah terjadi pergeseran menuju belanja online karena kemudahan, kenyamanan, kenyamanan, penghematan biaya, penghematan waktu dan pengiriman cepat dibandingkan dengan belanja konvensional atau tradisional. Konsumen tidak lagi terikat oleh waktu atau lokasi untuk melakukan transaksinya. Pembelian produk hanya dengan beberapa klik saja sebagai hasil pertumbuhan dan perkembangan yang cepat $e$ commerce.

Peningkatan aktivitas belanja online telah memaksa perusahaan untuk menawarkan produk dan layanan mereka secara online. Ini membantu mereka mendapatkan keunggulan kompetitif dibandingkan perusahaan lain di pasar. Tren global menunjukkan adanya pergeseran menuju e-commerce. Dengan demikian, popularitas e-commerce sebenarnya merupakan fenomena global. 


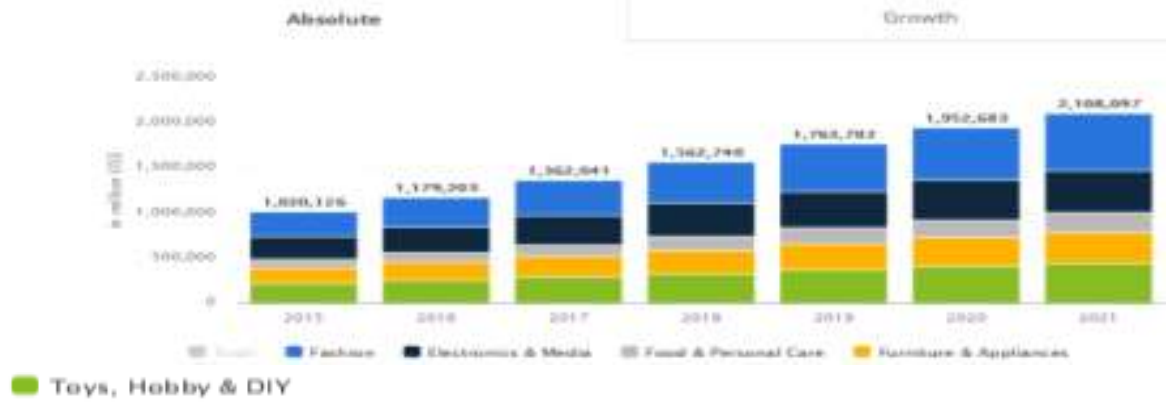

Gambar 1. Total Pendapatan Pasar e-commerce Di Seluruh Dunia

Sumber:https://www.statista.com/outlook/243/100/e-commerce/worldwide\#market-revenue

Berdasarkan Gambar 1.1 menunjukkan secara Statistik bahwa penjualan online (e-commerce) di seluruh dunia 2017 adalah sebesar US\$1.362.041.000.000 (US\$1.362 milyar atau setara dengan Rp 19.070 Triliun (dengan kurs US\$1 = Rp 14.000) dengan jenis golongan produk yang diperdagangkan berupa produk Fashion; Electronics \& Media; Food \& Personal care, Furniture \& Appliances, Toys, Hobby \& DIY (Do It Yourself). Dan tahun 2021 diprediksi berkembang sampai dengan US\$ 2.108.097.000.000 (US\$2.108,1 milyar atau setara dengan Rp.29.513,4 Triliun dengan kurs US\$1 = Rp14.000). Volume penjualan online terbesar di dunia adalah negara China dengan menyentuh US $\$ 470$ milyar atau setara dengan Rp6.580 Triliun (dengan kurs US\$1 = Rp14.000). Negara yang memiliki volume penjualan online e-commerce lima terbesar selanjutnya adalah Amerika Serikat, Inggris, Jepang dan Jerman. Sedangkan Indonesia volume penjualan online e-commerce yang berhasil diraih adalah sebesar US\$ 6,9627 milyar atau setara dengan Rp 97,5 Triliun (dengan kurs US\$1 = Rp14.000). seperti yang Nampak pada Gambar 1.2 berikut ini.
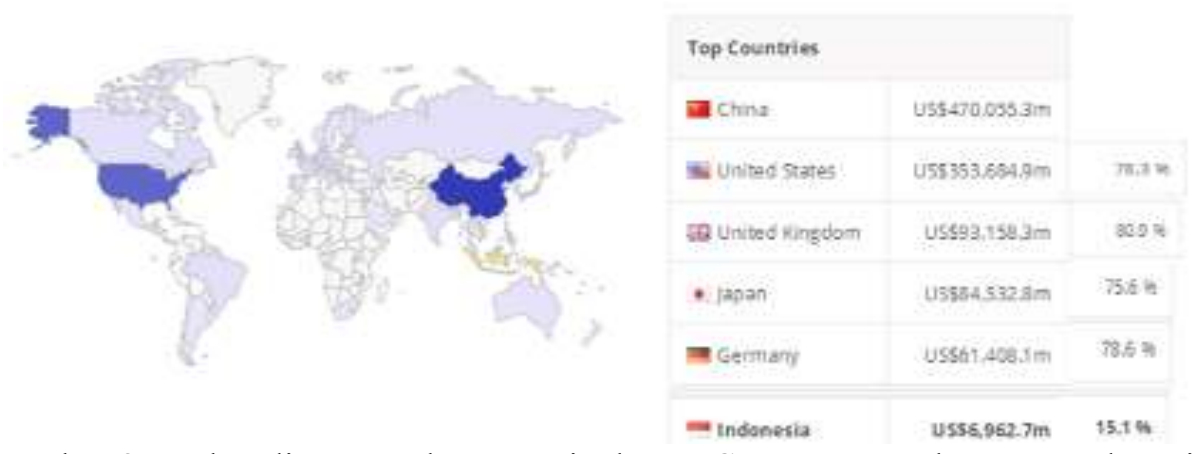

Gambar 2. Perbandingan Volume Penjualan E-Commerce Terbesar \& Indonesia Sumber: https://www.statista.com/outlook/243/120/e-commerce/indonesia\#market-global

Situs e-commerce yang banyak digunakan di Indonesia untuk belanja online yaitu: Lazada.co.id, Tokopedia.com, Bukalapak.com; OLX.com; Elevania.co.id; Shopee; Blibli.com; MatahariMall.com; Zalora.co.id; Traveloka.com; Amazon.com; Bhineka.com; Qoo10.co.id;; Jd.id; Agoda.com; id.Ebay.com; Jakartanotebook.com; dll.

Penelitian ini dibuat untuk meneliti faktor-faktor penentu pembelian online (e-commerce). Telah diamati bahwa perilaku pembelian online konsumen agak serupa di seluruh dunia. Faktor-faktor seperti keamanan, privasi, kualitas e-service, atribut produk, manfaat dan risiko yang dirasakan terkait dengan belanja online, dll merupakan factor yang mempengaruhi perilaku pembelian konsumen secara online di seluruh dunia. Disamping itu motivasi hedonis dan desain situs adalah prediktor perilaku online pembelian yang kuat di beberapa Negara. (Adnan, 2014)

Pengguna internet terbesar di dunia pada tahun 2019 adalah anak muda berusia 18 -24 tahun. Berdasarkan hasil penelitian lembaga riset dan survei dunia "Statisca.Inc" yang berkantor pusat di Hamburg Jerman, menyatakan bahwa usia $18-24$ tahun merupakan termasuk pengguna internet terbanyak ke-2 di seluruh dunia yaitu sebesar 18\%. (https://www.statista.com/statistics/272365/agedistribution-of-internet-users-worldwide).

Oleh karena itu penulis tertarik untuk melakukan penelitian mengenai perilaku pembelian online 
pada mahasiswa Fakultas Ekonomi dan Bisnis Universitas Palangka Raya, dimana mahasiswa rata-rata berusia 18-24 tahun dan merupakan golongan usia yang masuk kategori terbanyak ke-2 menggunakan internet di seluruh dunia. Disamping itu juga untuk mengetahui dan menganalisis faktor-faktor yang berpengaruh terhadap perilaku pembelian online konsumen mahasiswa.

\section{Tinjauan Pustaka}

\subsection{Manfaat yang dirasakan (Perceived Benefits)}

Soopramanien dan Robertson (2007) mengemukakan bahwa sikap terhadap belanja online bergantung pada pandangan konsumen mengenai aktivitas yang dilakukan di internet dibandingkan dengan lingkungan perbelanjaan konvensional. Studi telah menunjukkan bahwa kenyamanan dan penghematan waktu adalah alasan utama yang memotivasi konsumen berbelanja secara online. Chen et al. (2010) mengemukakan bahwa kenyamanan menunjukkan praktik belanja di internet yang bisa mengurangi waktu dan usaha konsumen dalam proses pembelian. E-commerce telah membuat pedagang mencari lebih mudah dengan mengurangi usaha dan waktu. Nazir dkk. (2012) menunjukkan bahwa belanja online lebih baik daripada belanja konvensional karena penggunaannya mudah dan sederhana, sehingga mendapatkan popularitas yang lebih tinggi. Salah satu variabel yang termasuk dalam model adalah manfaat yang dirasakan (Perceived Benefits) dan terbukti bahwa keuntungan yang dirasakan dari belanja online berdampak signifikan terhadap keinginan konsumen untuk melakukan transaksi online. Dengan demikian, keuntungan yang dirasakan mempengaruhi niat dan sikap membeli online konsumen. (Adnan, 2014)

\subsection{Risiko yang dirasakan (Perceived risk)}

Di sisi lain, konsumen juga mempertimbangkan risiko yang terkait dengan transaksi sebelum melakukan aktivitas ekonomi. Risiko ini bisa mencakup risiko keamanan, keuangan dan privasi. Chen et al. (2010) berpendapat bahwa risiko keamanan mempengaruhi niat pembelian online konsumen. Risiko finansial yang dipaparkan mengacu pada kemungkinan kerugian moneter akibat belanja di internet. Javadi dkk. (2012) mempelajari variabel yang mempengaruhi perilaku pembeli online di Iran, dan penelitian ini bertujuan untuk mengatasi kekurangan dari penelitian sebelumnya. 200 kuesioner online didistribusikan secara acak di antara beberapa toko online. Variabel yang dipelajari meliputi risiko produk, risiko keuangan, risiko kenyamanan, kebijakan pengembalian, persepsi terhadap belanja online, dll. Temuan penelitian menunjukkan bahwa variabel seperti risiko keuangan dan risiko non-pengiriman berdampak negatif pada pembeli internet. Dengan demikian, risiko yang dirasakan berdampak pada perilaku pembeli online.

\subsection{Faktor Psikologikal (Psychological factors)}

Selanjutnya, faktor psikologis (seperti masalah privasi dan masalah keamanan) dapat mempengaruhi niat pencarian dan pembelian pembeli online. Lee dan Huddleston (2010) berpendapat bahwa risiko privasi terkait dengan kekhawatiran kehilangan privasi karena konsumen harus mengungkapkan informasi pribadi mereka saat berbelanja secara online. Chen et al. (2010) oleh karena itu disarankan agar kontrol privasi diperlukan untuk menghapus masalah privasi pembeli online.

Nazir dkk. (2012) mempelajari variabel yang mempengaruhi perilaku belanja online konsumen Pakistan. Tujuan penelitian ini adalah untuk menganalisis berbagai faktor yang mempengaruhi perilaku pembelian internet dan untuk memahami mengapa konsumen ragu untuk berbelanja di internet. Metode survei digunakan untuk pengumpulan data. Kuesioner tertutup diisi dari sampel sebanyak 120 responden. Temuan tersebut mengungkapkan bahwa faktor sosial, psikologis, emosional dan privasi berpengaruh signifikan terhadap perilaku pembeli online. Masalah kepercayaan, keamanan dan privasi adalah beberapa masalah utama yang dihadapi pembeli online, seperti yang diidentifikasi oleh penelitian. Menurut penelitian, konsumen lebih memilih untuk tidak berbelanja secara online karena mereka meragukan kredibilitas prosedur transaksi dan pembayaran.

Sulaiman, Mohezar dan Rasheed (2007) melakukan penelitian empiris untuk membahas model kepercayaan untuk E-commerce di Pakistan. Penelitian ini bertujuan untuk menyelidiki peran yang dipercaya bermain dalam belanja online di pasar Pakistan. Kuesioner dibagikan di antara sampel 
250 responden. Kuesioner dibagi menjadi dua kategori, bagian pertama membahas pandangan responden tentang transaksi E-commerce sedangkan bagian kedua bertujuan mengumpulkan informasi demografis sampel. Salah satu variabel yang diamati adalah kepercayaan kepercayaan yang dirasakan vendor online. Temuan menunjukkan bahwa orang-orang yang berbelanja online memiliki tingkat kepercayaan yang lebih rendah terhadap kontrol privasi pengecer internet. Ini karena profil konsumen sering digunakan oleh pihak lain untuk tujuan pemasaran dan begitu konsumen mengetahui hal ini, mereka mengembangkan ketidakpercayaan terhadap vendor elektronik dan ini mencegah mereka melakukan transaksi online lagi. Studi tersebut menyimpulkan bahwa faktor-faktor yang mempengaruhi kepercayaan terhadap e-vendor mencakup keamanan, kompetensi, privasi, integritas, dan kecenderungan kepercayaan yang dirasakan.

\subsection{Motivasi Hedonik (Hedonic Motivations)}

Utami (2010) menyatakan bahwa motivasi hedonis adalah motivasi konsumen untuk berbelanja karena berbelanja merupakan suatu kesenangan tersendiri sehingga tidak memperhatikan manfaat dari produk yang dibeli. Childers dkk. (2002) menyelidiki faktor hedonik dan utilitarian yang mempengaruhi pembeli online. Sampel acak dari 1000 konsumen dipilih. Sampel terdiri dari orang-orang yang sadar akan lingkungan belanja online. Temuan penelitian ini menunjukkan bahwa ada beberapa prediktor kuat yang mencakup kenikmatan, navigasi, kenyamanan dan kegunaan.

Kim, Lee dan Kim (2004) menyelidiki faktor-faktor yang mempengaruhi pencarian online dan niat pembelian pembeli online. Kuesioner dibagikan di antara sampel dari 245 responden yang memiliki beberapa pengalaman menggunakan komputer dan internet untuk belanja online. Untuk menguji hipotesis, digunakan model hipotesis struktural. Temuan penelitian menunjukkan bahwa faktor-faktor seperti nilai utilitarian dan hedonik informasi dan pengalaman online merupakan penentu utama niat pencarian online konsumen.

\subsection{Disain Situs (Website design)}

Chen, dkk (2010) menyelidiki elemen situs web yang mengarah pada peningkatan niat beli. Tujuan dari penelitian ini adalah untuk menunjukkan struktur preferensi konsumen yang didasarkan pada fitur dan desain situs web. Sampelnya terdiri dari mahasiswa S1 dari universitas di Taiwan dan responden diminta untuk mengisi kuesioner online. Model gabungan kemudian digunakan untuk meneliti tanggapan. Temuan penelitian menunjukkan bahwa ada tiga kelompok responden yang tergolong berorientasi kegunaan, berorientasi pada keamanan dan berorientasi pada kenyamanan. Studi ini menemukan bahwa atribut ketiga kelompok tersebut menghargai pengiriman, kegunaan, kepercayaan, keamanan dan kenyamanan yang paling banyak disertakan. Responden juga lebih memilih antarmuka web yang mudah digunakan saat berbelanja online. Penelitian ini menyimpulkan lima fitur terpenting yang disorot dalam penelitian ini harus disertakan dalam situs web untuk meningkatkan niat beli konsumen.

Hausman dan Siekpe (2009) mencoba menentukan desain website tentang perilaku pembelian konsumen konsumen. Tujuan penelitian ini adalah untuk menyoroti faktor teknologi yang mendorong orang berbelanja secara online. Metode survei digunakan dan kuesioner diisi dari responden untuk menguji hubungan hipotesis. Temuan empiris penelitian ini menunjukkan bahwa elemen manusia dan komputer dari desain website berdampak pada niat beli konsumen. Hasil penelitian menunjukkan bahwa faktor komputer dan manusia memiliki hubungan positif dengan perceived usefulness. Penelitian ini menyimpulkan bahwa perancang internet harus berfokus pada penambahan fitur manusia seperti visual dan grafis yang menarik, model virtual $3 \mathrm{~d}$, dan lain-lain untuk menarik konsumen ke situs web mereka dan mendorong mereka melakukan pembelian secara online. Selain itu, fitur komputer juga harus difokuskan pada saat merancang situs web sehingga memudahkan konsumen memahami tata letak, menavigasi, mencari informasi secara online dan mengurangi iritasi yang dihadapi konsumen saat browsing online. Bai, Law dan Wen (2008) melakukan penelitian yang bertujuan untuk meneliti dampak kualitas situs web terhadap niat konsumen untuk melakukan pembelian secara online. Pengunjung online di China digunakan untuk melakukan penelitian karena China memiliki pasar online yang besar. Metode survei digunakan. Temuan penelitian menunjukkan bahwa kualitas website memiliki hubungan positif yang signifikan dengan niat beli. Juga, kepuasan pelanggan ditemukan untuk menengahi efek ini. Penelitian ini menyimpulkan bahwa penting bagi 
perusahaan untuk berinvestasi dalam kualitas situs web mereka untuk menarik dan mempertahankan pembeli online.

\subsection{Kerangka Pemikiran}

Berdasarkan pemaparan tersebut di atas, dapat digambarkan kerangka pemikir sebagai berikut.

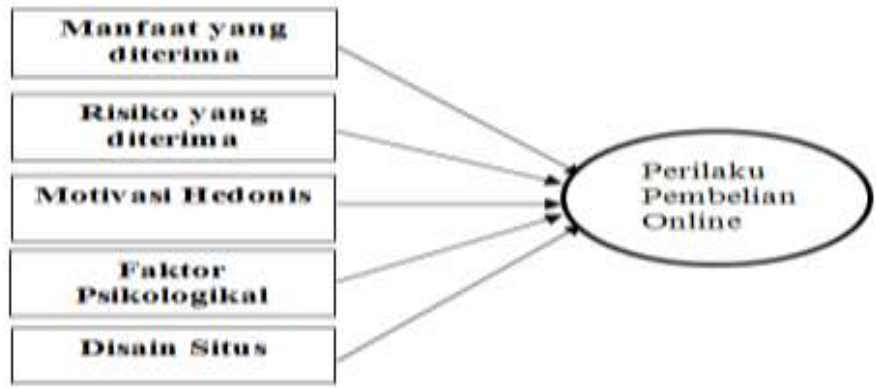

Gambar 3. Kerangka Pemikiran

Sumber : Adnan (2014) dikembangkan untuk penelitian ini (2021)

\section{Metode Penelitian}

Populasi dalam penelitian ini adalah seluruh mahasiswa FEB UPR yang menggunakan jasa pembelian online. Metode pengambilan sampel menggunakan convenience sampling yaitu metode yang mengumpulkan informasi dari anggota populasi yang mudah didapatkan. Di samping itu juga karena pertimbangan kemudahan dalam memperoleh subyek sampel, cepat, dan tidak memerlukan biaya yang besar tanpa banyak mengurangi ketepatan pengukuran. Besarnya sampel dalam penelitian ini adalah berdasar pertimbangan dari Roscoe (1975) dalam Sekaran (2016) memberikan rule of thumb, yaitu besarnya sampel yang lebih dari 30 dan lebih kecil dari 500 sudah mencukupi untuk suatu penelitian. Sampel penelitian ini akan diambil dari konsumen mahasiswa Fakultas Ekonomi dan Bisnis Universitas Palangka Raya yang merupakan pembeli online dengan jumlah sebanyak 100 orang responden. Sumber data berasal dari data primer yang diperoleh melalui penyebaran kuesioner untuk dijawab oleh responden yang sudah dipersiapkan terlebih dahulu oleh peneliti.

Definisi Operasional Variabel dalam penelitian ini adalah:

1. Keuntungan yang dirasakan dengan konstruksi meliputi kemudahan, kenyamanan, ketersediaan, dll diukur dengan skala likert 1-5.

2. Risiko yang dirasakan dengan konstruksi mencakup risiko produk, risiko kenyamanan, risiko nonpengiriman, dll, diukur dengan skala likert 1-5.

3. Motivasi Hedonik dengan kontruksi mencakup kenikmatan, diukur dengan skala likert 1-5.

4. Faktor psikologis dengan konstruksi meliputi kepercayaan, keamanan dan privasi, diukur dengan skala likert 1-5.

5. Desain situs web dengan konstruksi meliputi estetika, faktor isi dan desain transaksional, diukur dengan skala likert 1-5.

6. Variabel dependen: Perilaku pembelian konsumen online, diukur dengan skala likert 1-5.

Instrumen penelitian yang digunakan dalam penelitian ini diukur kelayakannya dengan uji validitas dan reliabilitas. Uji validitas dengan korelasi pearson yaitu dengan cara mengkorelasikan skor item dengan skor total item, kemudian pengujian signifikansi dilakukan dengan kriteria menggunakan $r$ tabel pada tingkat signifikansi 0,05 dengan uji 2 sisi. Jika nilai positif dan $r$ hitung $>r$ tabel maka item dapat dinyatakan valid, jika $r$ hitung $<\mathrm{r}$ tabel maka item dinyatakan tidak valid. Uji Reliabilitas dilakukan dengan teknik Cronbach Alpha, yaitu untuk menentukan suatu instrumen reliabel atau tidak maka bisa menggunakan batas nilai Alpha 0,6 (Cronbach Alpha > 0,06). (Priyatno, 2012).

Pengujian Asumsi Klasik dilakukan dengan pengujian asumsi normalitas, multikolinearitas, heteroskedastisitas. Manfaat uji asumsi klasik adalah agar hasil regresi tidak menyimpang atau bias. Tehnik analisis data yang digunakan adalah analisis regresi linier berganda untuk mengetahui seberapa besar pengaruh variabel bebas yaitu: Manfaat yang diterima, Risiko yang diterima, Motivasi Hedonis, Faktor Psikologikal, Disain Situs terhadap variabel terikatnya yaitu Perilaku Pembelian Konsumen Online. Persamaan regresi linier berganda adalah sebagai berikut: 


$$
Y=a+b_{1} X_{1}+b_{2} X_{2}+b_{3} X_{3}+b_{4} X_{4}+b_{5} X_{5}+\varepsilon
$$

Dimana:

$$
\begin{array}{ll}
\mathrm{Y} & =\text { Variabel dependen } \\
\mathrm{a} & =\text { Konstanta } \\
\mathrm{b}_{1}, \mathrm{~b}_{2}, \mathrm{~b}_{3}, \mathrm{~b}_{4}, \mathrm{~b}_{5} & =\text { Koefisien regresi } \\
\mathrm{X}_{1}, \mathrm{X}_{2}, \mathrm{X}_{3}, \mathrm{X}_{4}, \mathrm{X}_{5} & =\text { Variabel independen } \\
\varepsilon & =\text { error/ variabel pengganggu }
\end{array}
$$

\section{Hasil Penelitian}

Karakteristik responden berdasarkan jenis kelamin, yaitu responden wanita sebanyak 52 orang atau $52 \%$, sedangkan responden pria sebanyak 48 orang atau $48 \%$. Karakteristik responden

\begin{tabular}{|c|c|c|c|c|}
\hline Var & Pernyataan & Mean & $\mathrm{r}$ & $\begin{array}{c}\text { Cronbach } \\
\text { Alpha }\end{array}$ \\
\hline \multirow{7}{*}{ XI } & $\begin{array}{l}\text { Saya berbelanja online karena saya bisa berbelanja kapan pun saya } \\
\text { mau. }\end{array}$ & 4,14 & $.779 "$ & .949 \\
\hline & $\begin{array}{l}\text { Saya berbelanja online saat mendapatkan informasi produk secara } \\
\text { online. }\end{array}$ & 4,35 & $.776^{\prime \prime}$ & .949 \\
\hline & $\begin{array}{l}\text { Saya berbelanja online karena saya mendapatkan pilihan produk yang } \\
\text { lebih luas tersedia. }\end{array}$ & 4,05 & $.710 "$ & .950 \\
\hline & Belanja online memberi fasilitas perbandingan harga yang mudah & 4,39 & $.737^{\prime \prime}$ & .950 \\
\hline & Saya berbelanja saat saya mendapatkan ulasan dari pengguna & 4,27 & $.788^{\prime \prime}$ & .950 \\
\hline & $\begin{array}{l}\text { Saya menggunakan belanja online untuk membeli produk yang } \\
\text { sebaliknya yang tidak mudah didapat di pasar }\end{array}$ & 4,01 & $.725 “$ & .950 \\
\hline & $\begin{array}{l}\text { Saya berbelanja online karena ada lebih banyak pilihan pembayaran } \\
\text { yang tersedia. }\end{array}$ & 4,19 & $.803^{\prime \prime}$ & .949 \\
\hline \multirow{6}{*}{$\mathrm{X} 2$} & $\begin{array}{l}\text { Saya ragu untuk berbelanja online karena ada resiko tinggi untuk } \\
\text { menerima barang pesanan yang tidak berfungsi }\end{array}$ & 4,12 & $.760 "$ & .948 \\
\hline & Saya tidak suka dikenai biaya pengiriman saat berbelanja online & 4,25 & $.861^{66}$ & .948 \\
\hline & $\begin{array}{l}\text { Saya merasa akan ada kesulitan dalam menyelesaikan komplain saat } \\
\text { berbelanja online. }\end{array}$ & 4,10 & $.796 "$ & .949 \\
\hline & Saya mungkin tidak menerima barang yang dipesan secara online & 4,21 & $.624 "$ & .952 \\
\hline & Saya sulit menilai kualitas barang pesanan lewat internet. & 4,34 & $.755^{1 *}$ & .950 \\
\hline & $\begin{array}{l}\text { Mendapatkan layanan purna jual yang baik sangat menyita waktu dan } \\
\text { menyulitkan pembelian online. }\end{array}$ & 4,26 & $.855^{\prime \prime}$ & 949 \\
\hline \multirow[t]{3}{*}{$\mathrm{X} 3$} & $\begin{array}{l}\text { Mencari informasi produk di internet adalah cara yang baik untuk } \\
\text { menghabiskan waktu }\end{array}$ & 4,11 & ,808“" & .949 \\
\hline & $\begin{array}{l}\text { Pencarian Informasi di internet itu menyenangkan bukan } \\
\text { membosankan. }\end{array}$ & 4,19 & $.889 "$ & .948 \\
\hline & Belanja online sangat menyenangkan. & 4,23 & $.842^{\prime \prime}$ & 949 \\
\hline \multirow{3}{*}{$\mathrm{X} 4$} & Saya tidak ditagih berlebihan jika saya berbelanja online & 4,04 & .795 & .950 \\
\hline & $\begin{array}{l}\text { Saya merasa bahwa informasi pribadi saya tidak mungkin } \\
\text { dimanfaatkan oleh pihak ketiga }\end{array}$ & 4,14 & $.830^{\circ}$ & .949 \\
\hline & $\begin{array}{l}\text { Belanja online tidak berisiko karena adanya hukum cyber yang ketat } \\
\text { untuk menghukum penipuan dan hacker. }\end{array}$ & 4,13 & $.833^{\prime \prime}$ & .949 \\
\hline \multirow{3}{*}{ X5 } & $\begin{array}{l}\text { Saya membeli dari toko online hanya jika barangnya secara visual } \\
\text { menarik }\end{array}$ & 4,23 & $.690^{6}$ & .948 \\
\hline & $\begin{array}{l}\text { Saya membeli dari toko online hanya jika penggunaan produknya } \\
\text { nyaman bagi pengguna. }\end{array}$ & 4,32 & $.682^{\prime \prime}$ & .949 \\
\hline & $\begin{array}{l}\text { Saya membeli dari toko online hanya jika konten situs itu } \\
\text { memudahkan bagi saya untuk mengerti dan informasi yang diberikan } \\
\text { relevan. }\end{array}$ & 3,86 & $.669 "$ & .954 \\
\hline
\end{tabular}
berdasarkan jurusan, yaitu responden jurusan Akuntansi sebanyak 40 orang ( $40 \%$ ), jurusan Manajemen sebanyak 35 orang (35\%), dan jurusan Ekonomi Pembangunan sebanyak 25 orang (25 \%).

Berikut ini disajikan hasil uji vaiiditas berdasarkan hasil nilai Pearson Correlation (r) yang disajikan pada Tabel 4.1 sebagai berikut:

Tabel 1. Item, Means, Pearson Correlation (r), dan Cronbach Alpha 
IEMBA : Jurnal Ekonomi Pembangunan, Manajemen dan Bisnis, Akuntansi

Volume 1 Nomor 2 ( Juni 2021 ) / e-journal.upr.ac.id

\begin{tabular}{|c|c|c|c|c|}
\hline \multirow[t]{2}{*}{ Var } & Pernyataan & Mean & $r$ & $\begin{array}{c}\text { Cronbach } \\
\text { Alpha }\end{array}$ \\
\hline & $\begin{array}{l}\text { Saya membeli dari toko online hanya jika toko online memiliki } \\
\text { kemudahan dan bebas dari kesalahan prosedur pemesanan }\end{array}$ & 3,64 & $.630^{6}$ & .954 \\
\hline \multirow{4}{*}{ Y } & Menggunakan Internet untuk belanja online itu mudah. & 4,29 & $.808 "$ & .950 \\
\hline & $\begin{array}{l}\text { Ketika saya melakukan pembelian, pendapat teman dan keluarga } \\
\text { adalah penting bagi saya }\end{array}$ & 4,26 & $.831 "$ & .949 \\
\hline & $\begin{array}{l}\text { Saya tidak bermasalah dalam belanja online jika mengetahui bahwa } \\
\text { teman dan kerabat saya melakukannya tanpa masalah. }\end{array}$ & 4,22 & $.852^{\prime \prime}$ & .949 \\
\hline & $\begin{array}{l}\text { Saya tidak akan berbelanja online jika waktu download laman } \\
\text { situsnya lambat. }\end{array}$ & 4,10 & $.677^{\prime \prime}$ & .950 \\
\hline
\end{tabular}

Sumber: Data Primer diolah (2021)

Berdasarkan hasil perhitungan SPSS pada Tabel 1 di atas, diketahui semua item hasil $\mathrm{r}_{\text {hitung }}$ adalah signifikan pada level 5\%, dimana hasil $\mathrm{r}_{\text {hitung }}>\mathrm{f}_{\text {tabel }}=0,1966(\mathrm{df}=98 ; 0,05)$ sehingga semua item adalah valid. Dan koefisien alpha Cronbach semua item $>0,70$ sehingga semua item adalah reliabel.

Uji normalitas data Berdasarkan hasil uji normalitas dengan menggunakan One-Sample Kolmogorov-Smirnov Test menunjukkan bahwa nilai Asymp Sig. (2-Tailed) memiliki nilai sebesar 0,158 dimana nilai ini lebih besar dari 5\% $(0,05)$ sehingga dapat disimpulkan bahwa data kuesioner yang digunakan sudah berdistribusi normal. Uji Multikolonieritas dapat dilihat dari nilai tolerance yang berada di atas 0,10. Dan nilai VIF di bawah 10. Hal ini menunjukkan bahwa dalam model regresi tidak terdapat multikolonieritas. Hasil uji Heteroskedastisitas dapat dikatakan bahwa dalam model regresi tidak terdapat masalah heterokedastisitas karena penyebaran titik-titik tersebar secara merata dibawah dan di atas angka nol. Hasil analisis regresi linier berganda dengan program SPSS, seperti terlihat pada Tabel 2, berikut ini.

Tabel 2. Hasil Analisis Regresi Linier Berganda

\begin{tabular}{|l|c|c|c|c|c|c|c|}
\hline \multirow{2}{*}{ Model } & \multicolumn{2}{|c|}{$\begin{array}{c}\text { Unstandardized } \\
\text { Coefficients }\end{array}$} & $\begin{array}{c}\text { Standardized } \\
\text { Coefficients }\end{array}$ & $\mathrm{t}$ & \multicolumn{2}{|c|}{ Sig } & \multicolumn{2}{|c|}{ Collinearity Statistics } \\
\cline { 2 - 4 } & $\mathrm{B}$ & Std. Error & Beta & & & Tolerance & VIF \\
\hline 1 (Constant) & .147 & .236 & & .625 & .533 & & \\
V AR_X1 & .172 & 076 & .172 & 2.261 & .026 & .350 & 2.859 \\
VARX2 & .242 & .086 & .244 & 2.827 & .006 & .270 & 3699 \\
VAR_X3 & .333 & .073 & .378 & 4.579 & .000 & .296 & 3.374 \\
VAR_X4 & .334 & .076 & .349 & 4.402 & .000 & .321 & 3.113 \\
VARX5 & .253 & .072 & .213 & 3.499 & .001 & .543 & 1.843 \\
\hline
\end{tabular}

a Dependent Variable: VAR Y

Sumber : Data Primer diolah (2021)

Hasil analisis regresi linier berganda dengan program SPSS, seperti terlihat pada Tabel 4.2, di atas pada kolom Unstandardized Coefficients bagian B, maka diperoleh persamaan regresi linier berganda sebagai berikut: Perilaku Pembelian Konsumen Online $=0,147+0,172$ Manfaat yang diterima $+0,242$ Risiko yang diterima $+0,333$ Motivasi Hedonis $+0,334$ Faktor Psikologikal $+0,253$ Disain Situs.

Uji koefisien determinasi digunakan untuk menguji goodness of fit model regresi. Berdasarkan hasil output SPSS besamya nilai adjusted $R^{2}$ dapat dilihat pada tabel berikut:

Tabel 3. Model Summary

\begin{tabular}{|l|r|r|r|r|}
\hline Model & \multicolumn{1}{|c|}{ R } & R Square & Adjusted R Square & Std. Error of the Estimate \\
\hline 1 & $.900 *$ & .811 & .801 & .19414 \\
\hline
\end{tabular}

a. Predictors: (Constant), VAR_X1, VAR_X2, VAR_X3, VAR_X4, VAR_X5

b Dependent Variable: VAR Y

Sumber: Data Primer diolah (2021) 
Berdasarkan tabel 3. di atas, nilai adjusted $\mathrm{R}$ : sebesar 0,801 atau 80,1\%. Hal ini berarti $80,1 \%$ variabel dependen (Perilaku Pembelian Konsumen Online) dapat dijelaskan oleh kelima variabel independen (Manfaat yang diterima, Risiko yang diterima, Motivasi Hedonis, Faktor Psikologikal, dan Disain Situs), sedangkan sisanya $100 \%-80,1 \%=19,9 \%$ dijelaskan oleh variabel atau faktor- faktor lain di luar model.

Berdasarkan Tabel 2 di atas pada kolom t dan kolom sig. maka hasil uji hipotesisnya adalah sebagai berikut:

HI: Manfaat yang diterima berpengaruh signifikan terhadap Perilaku Pembelian Konsumen Online

Berdasarkan hasil perhitungan uji secara parsial diperoleh nilai thitung $=-2,261>\mathrm{t}_{\text {tabel }}=$ $1,985251(\mathrm{df}=95 ; 0,05)$ dan nilai signifikansi/probabilitas sebesar 0,026 $<0,05,(a=5 \%)$ maka hipotesis (HI) adalah diterima.

H2: Risiko yang diterima berpengaruh signifikan terhadap terhadap Perilaku Pembelian Konsumen Online

Berdasarkan hasil perhitungan uji secara parsial diperoleh nilai $t_{\text {hitung }}=2,827>t_{\text {tabel }}=1,985251$ $(\mathrm{df}=95 ; 0,05)$ dan nilai signifikansi/probabilitas sebesar $0,006<0,05,(\mathrm{a}=5 \%)$ maka hipotesis $(\mathrm{H} 2)$ adalah diterima.

H3: Motivasi Hedonis berpengaruh signifikan terhadap terhadap Perilaku Pembelian Konsumen Online Berdasarkan hasil perhitungan uji secara parsial diperoleh nilai thitung $=4,579>\mathrm{t}_{\text {hitung }}=$ $1,985251(\mathrm{df}=95 ; 0,05)$ dan nilai signifikansi/probabilitas sebesar $0,000<0,05(\mathrm{a}=5 \%)$ maka hipotesis (H3) adalah diterima.

H4: Faktor Psikologikal berpengaruh signifikan terhadap terhadap Perilaku Pembelian Konsumen Online

Berdasarkan hasil perhitungan uji secara parsial diperoleh nilai thitung $=4,402>$ ttabel $=$ $1,985251(\mathrm{df}=95 ; 0,05)$ dan nilai signifikansi/probabilitas sebesar $0,000<0,05(\mathrm{a}=5 \%)$ maka hipotesis (H4) adalah diterima.

H5: Disain Situs berpengaruh signifikan terhadap terhadap Perilaku Pembelian Konsumen Online

Berdasarkan hasil perhitungan uji secara parsial diperoleh nilai $\mathrm{t}_{\text {hitung }}=3,499>\mathrm{t}_{\text {tabel }}=1,985251$ $(\mathrm{df}=95 ; 0,05)$ dan nilai signifikansi/probabilitas sebesar 0,001 $<0,05(\mathrm{a}=5 \%)$ maka hipotesis $(\mathrm{H} 5)$ adalah diterima.

Hasil perhitungan uji F dalam penelitian ini dapat dilihat pada tabel berikut:

Tabel 4. ANOVA ${ }^{\mathrm{b}}$

\begin{tabular}{|c|r|r|r|c|c|}
\hline Model & Sum of Squares & \multicolumn{1}{c|}{ df } & Mean Square & F & Sig \\
\hline 1 Regression & 15.163 & 5 & 3.033 & 80.466 & 0.000 \\
Residual & 3.543 & 94 & .038 & & \\
Total & 18.706 & 99 & & & \\
\hline
\end{tabular}

a. Predictors: (Constant), VAR_X1, VAR_X2, VAR_X3, VAR_X4, VAR_X5

b. Dependent Variable: VAR Y

Sumber : Data Primer diolah (2021)

Berdasarkan hasil output SPSS pada tabel 4.4, di atas dapat diketahui bahwa variabel Manfaat yang diterima, Risiko yang diterima, Motivasi Hedonis, Faktor Psikologikal, Disain Situs secara simultan/bersama-sama memiliki pengaruh yang signifikan terhadap variabel Perilaku Pembelian Konsumen Online. Hal ini dapat dibuktikan dari nilai signifikansi sebesar 0,000<0,05 $(\mathrm{a}=5 \%)$ dan nilai $\mathrm{F}_{\text {hitung }}=80,466>\mathrm{F}_{\text {tabel }}=2,467494$. sehingga hipotesis secara simultan adalah diterima.

Manfaat yang diterima berpengaruh signifikan terhadap Perilaku Pembelian Konsumen Online adalah diterima. Temuan ini sesuai dengan temuan Adnan (2011), dan Iqbal, Rahman dan Hunjra (2012) Yang menyatakan bahwa Manfaat yang dirasakan adalah salah satu variabel yang mempengaruhi perilaku belanja online. Variabel Manfaat yang diterima dapat mencakup yaitu: berbelanja online dapat memberi fasilitas perbandingan harga yang mudah. Item ini merupakan item paling besar kontribusinya untuk variabel Manfaat yang diterima, sehingga benar- benar menjadi perhatian dan prioritas bagi bisnis online. Di samping itu, belanja online bisa kapan saja, mendapatkan 
informasi produk secara online, mendapatkan pilihan produk yang lebih luas tersedia, mendapatkan ulasan dari pengguna, untuk membeli produk yang sebaliknya yang tidak mudah didapat di pasar, dan ada lebih banyak pilihan pembayaran yang tersedia

Risiko yang diterima berpengaruh signifikan terhadap terhadap Perilaku Pembelian Konsumen Online adalah diterima . Temuan ini sesuai dengan temuan Adnan (2011), Iqbal, Rahman dan Hunjra (2012) yang menyatakan bahwa risiko yang diterima mempengaruhi perilaku pembelian online. Risiko yang diterima dapat mencakup: sulit menilai kualitas barang pesanannya lewat internet. Item ini merupakan item paling besar kontribusinya untuk variabel Risiko yang diterima, sehingga benar-benar menjadi perhatian dan prioritas bagi bisnis online. Di samping itu, tidak suka dikenai biaya pengiriman saat berbelanja online, berbelanja online berisiko tinggi menerima barang pesanan yang tidak berfungsi, merasa akan ada kesulitan dalam menyelesaikan komplain saat berbelanja online, mungkin tidak menerima produk yang dipesan secara online, mendapatkan layanan purna jual yang baik sangat menyita waktu dan menyulitkan pembelian online.

Motivasi Hedonis berpengaruh signifikan terhadap terhadap Perilaku Pembelian Konsumen Online adalah diterima. Temuan ini sesuai dengan temuan Kim, Lee, Kim (2004) yang menyatakan bahwa Motivasi Hedonis berpengaruh signifikan terhadap terhadap Perilaku Konsumen Online. Motivasi Hedonis dapat mencakup: Belanja online adalah sangat menyenangkan. Item ini merupakan item paling besar kontribusinya untuk variabel Motivasi Hedonis, sehingga benar-benar menjadi perhatian dan prioritas bagi bisnis online. Di samping itu, Pencarian Informasi di internet adalah tidak membosankan, dan mencari informasi produk di internet adalah cara yang baik untuk menghabiskan waktu.

Faktor Psikologikal berpengaruh signifikan terhadap terhadap Perilaku Pembelian Konsumen Online adalah diterima. Temuan ini sesuai dengan temuan Adnan (2011), serta Iqbal, Rahman dan Hunjra (2012) yang menyatakan bahwa Faktor Psikologikal berpengaruh signifikan terhadap terhadap Perilaku Pembelian Konsumen Online. Faktor Psikologikal dapat mencakup: dalam belanja online informasi pribadi tidak mungkin dimanfaatkan oleh pihak ketiga. Item ini merupakan item paling besar kontribusinya untuk variabel Faktor Psikologikal, sehingga benar-benar menjadi perhatian dan prioritas bagi bisnis online. Di samping itu, dalam berbelanja online tidak berisiko karena adanya hukum cyber yang ketat untuk menghukum penipuan dan hacker, serta tidak ditagih berlebihan jika berbelanja online.

Disain Situs berpengaruh signifikan terhadap terhadap Perilaku Pembelian Konsumen Online adalah diterima. Temuan ini sesuai dengan temuan Iqbal, Rahman dan Hunjra (2012) yang menyatakan bahwa Disain Situs berpengaruh signifikan terhadap terhadap Perilaku Pembelian Konsumen Online. Disain Situs dapat mencakup: berbelanja online pada toko online hanya jika penggunaan produknya nyaman bagi pengguna, Item ini merupakan item paling besar kontribusinya untuk variabel Disain Situs, sehingga benar-benar menjadi perhatian dan prioritas bagi bisnis online. Di samping itu, berbelanja online pada toko online hanya jika barangnya secara visual menarik, hanya jika konten situs itu memudahkan bagi saya untuk mengerti dan informasi yang diberikan relevan, hanya jika toko online memiliki kemudahan dan bebas dari kesalahan prosedur pemesanan.

Berdasarkan hasil output SPSS pada tabel 4.4 di atas dapat diketahui bahwa variabel Manfaat yang diterima, Risiko yang diterima, Motivasi Hedonis, Faktor Psikologikal, Disain Situs secara simultan/bersama-sama memiliki pengaruh yang signifikan terhadap variabel Perilaku Pembelian Konsumen Online. Sehingga semua variable tersebut secara bersama-sama sangat berarti dalam mempengaruhi pembelian online. Walaupun demikian untuk mengetahui faktor/variabel yang paling dominan mempengaruhi pembelian online maka dapat diketahui dengan melihat nilai t hitung masingmasing variabel yaitu: Manfaat yang diterima $=2,261$, Risiko yang diterima $=2,827$, Motivasi Hedonis $=4,579$, Faktor Psikologikal $=4,402$, dan Disain Situs $=3,499$. Karena Motivasi Hedonis memiliki nilai thitung yang paling besar yaitu 4,579 maka dapat disimpulkan bahwa dalam penelitian ini variabel Motivasi Hedonis berpengaruh dominan terhadap Perilaku Pembelian online bila dibandingkan dengan variabel bebas lainnya. Sehingga untuk meningkatkan Perilaku Pembelian online konsumen mahasiswa perlu memprioritaskan Variabel Motivasi Hedonis konsumen.

Berdasarkan nilai adjusted $\mathrm{R}$ pada Tabel 4.3 di atas, sebesar 0,801 atau $80,1 \%$. Hal ini berarti $80,1 \%$ variabel dependen (Perilaku Pembelian Konsumen Online) dapat dijelaskan oleh kelima variabel independen (Manfaat yang diterima, Risiko yang diterima, Motivasi Hedonis, Faktor Psikologikal, dan 
Disain Situs), sedangkan sisanya 100\% - 80,1\% = 19,9\% dijelaskan oleh variabel atau faktor-faktor lain di luar model. Sehingga Evaluasi terhadap model disimpulkan sudah baik. Akan tetapi karena ruang lingkup penelitian sangat kecil yaitu hanya pada mahasiswa Fakultas Ekonomi Universitas Palangka Raya. Maka untuk penelitian selanjutnya dengan tema yang sama dapat memperluas ruang lingkup penelitian dan menambah sampel penelitian seperti misalnya pada pelanggan kota atau kabupaten di Kalimantan Tengah.

\section{KESIMPULAN}

Variabel Manfaat yang diterima berpengaruh signifikan terhadap Perilaku Pembelian Konsumen Online adalah diterima. Risiko yang diterima berpengaruh signifikan terhadap terhadap Perilaku Pembelian Konsumen Online adalah diterima. Motivasi Hedonis berpengaruh signifikan terhadap terhadap Perilaku Pembelian Konsumen Online adalah diterima. Faktor Psikologikal berpengaruh signifikan terhadap terhadap Perilaku Pembelian Konsumen Online adalah diterima. Disain Situs berpengaruh signifikan terhadap terhadap Perilaku Pembelian Konsumen Online adalah diterima. Variabel Manfaat yang diterima, Risiko yang diterima, Motivasi Hedonis, Faktor Psikologikal, dan Disain Situs secara simultan berpengaruh signifikan terhadap Perilaku Pembelian Konsumen Online.

\section{Referensi}

Adnan, Hooria. (2014). An Analysis of the Factors Affecting Online Purchasing Behavior of Pakistani Consumers. International Journal of Marketing Studies 6(5), 133-148. http://dx.doi.org/10.5539/ijms.v6n5p133

Bai, B., Law, R., \& Wen, I. (2008). The impact of website quality on customer satisfaction and purchase intentions: Evidence from Chinese online visitors. International Journal of Hospitality Management, 27(3), 391-402.

Chen, Y. H., Hsu, I., \& Lin, C. C. (2010). Website Attributes That Increase Consumer Purchase Intention: A Conjoint Analysis. Journal of business research, 63(9), 1007-1014.

Childers, T. L., Carr, C. L., Peck, J., \& Carson, S. (2002). Hedonic And Utilitarian Motivations For Online Retail Shopping Behavior. Journal of retailing, 77(4), 511-535.

Close, A. G., \& Kukar-Kinney, M. (2010). Beyond Buying: Motivations Behind Consumers' Online Shopping Cart Use. Journal of Business Research, 63(9), 986-992.

Hausman, A. V., \& Siekpe, J. S. (2009). The effect of web interface features on consumer online purchase intentions. Journal of business research, 62(1), 5-13.

Iqbal, S., Hunjra, A. I., \& Rehman, K. U. (2012). Consumer intention to shop online: B2C E-commerce in developing countries. Middle-East Journal of Scientific Research, 12(4), 424-432.

Javadi, M. H., Dolatabadi, H. R., Nourbakhsh, M., Poursaeedi, A., \& Asadollahi, A. R. (2012). An Analysis of Factors Affecting on Online Shopping Behavior of Consumers. International Journal of Marketing Studies, 4(5), 81-98.

Kim, J., Lee, H. C., \& Kim, H. J. (2004). Factors Affecting Online Search Intention and Online Purchase Intention. Seoul Journal of Business, 10(2), 27-48. Retrieved from http://sspace.snu.ac.kr/bitstream/10371/1809/1/SJBv10n2_027.pdf

Lee, H. J., \& Huddleston, P. T. (2010). An investigation of the relationships among domain-specific innovativeness, overall perceived risk and online purchase behavior. International Journal of Electronic Marketing and Retailing, 3(1), 1-4.

Nazir, S., Tayyab, A., Sajid, A., \& Javed, I. (2012). How Online Shopping Is Affecting Consumers Buying Behavior in Pakistan?. International Journal of Computer Science Issues (IJCSI), 9(3), 486-495. Retrieved from http://ijcsi.org/papers/IJCSI-9-3-1-486-495.pdf 
Priyatno, Duwi. 2012. Analisis Data dengan SPSS 20. Yogyakarta: Penerbit Andi

Sekaran, U. \& Bougie, R. (2016). Research methods for business. A sill building approach (7th ed.) John Willey: UK

Soopramanien, D. G. R., \& Robertson, A. (2007). Adoption and usage of online shopping: An empiricalanalysis of the characteristics of "buyers" "browsers" and "non-internet shoppers". Journal of Retailing and Consumer Services, 14(1), 73-82.

Sulaiman, A., Mohezar, S., \& Rasheed, A. (2007). A Trust Model for E-Commerce in Pakistan: An Empirical Research. Asian Journal of Information Technology, 6(2), 192-199.

https://www.statista.com/outlook/243/100/e-commerce/worldwide\#market-revenue_<diakses September 2019>

https://www.statista.com/outlook/243/120/e-commerce/indonesia\#market-global_<diakses September 2019>

https://www.statista.com/statistics/272365/age-distribution-of-internet-users-worldwide $<$ diakses April 2021> 